\title{
Analysing student engagement with learning and tutoring activities in networked learning communities: a multi-method approach
}

\author{
Maarten De Laat* \\ School of Education and Lifelong Learning \\ University of Exeter, St. Luke's Campus \\ Heavitree Road, EX1 2LU, Exeter, UK \\ E-mail:m.f.delaat@exeter.ac.uk \\ *Corresponding author
}

\section{Vic Lally}

Networked Learning Research Group

University of Sheffield

388, Glossop Road, S10 2JA, Sheffield, UK

E-mail: v.lally@shef.ac.uk

\section{Lasse Lipponen}

Department of Applied Sciences of Education University of Helsinki

P.O. Box 9

00014 University of Helsinki, Finland

E-mail: lasse.lipponen@helsinki.fi

\section{Robert-Jan Simons}

Centre for ICT in Education, IVLOS

University of Utrecht

P.O. Box 80127

3508 TC Utrecht, The Netherlands

E-mail: p.r.j.simons@ivlos.uu.nl

\begin{abstract}
The aim of this paper is to study the nature of teaching and learning processes in two Networked Learning Communities (NLCs). The study undertakes empirical work using a multi-method approach in order to triangulate and contextualise our findings and enrich our understanding of the student participation in these NLCs. We apply Social Network Analysis (SNA) to visualise the social structure of the NLC, Content Analysis (CA) to identify learning and teaching processes and Context Analysis (CxA) to study students' personal experiences and intentions. The paper reports some of the current findings of this work and discusses future prospects. This paper is part of a continuing international study that is investigating networked collaborative learning among a community of learners engaged in a master's programme in e-learning.
\end{abstract}


Keywords: networked learning; online tutoring; multi-method; triangulation; computer-mediated communication.

Reference to this paper should be made as follows: De Laat, M., Lally, V., Lipponen, L. and Simons, R-J. (2006) 'Analysing student engagement with learning and tutoring activities in networked learning communities: a multi-method approach', Int. J. Web Based Communities, Vol. 2, No. 4, pp.394-412.

Biographical notes: Dr. Maarten de Laat is a principal researcher at the school of education and lifelong learning at Exeter University. He conducts research on e-learning in both educational and organisational contexts. His work covers networked learning, CSCL, ICT, communities of practice, social learning, work related learning and knowledge management. Besides working for the University of Exeter, he also works for the Centre for ICT in Education at IVLOS, University of Utrecht, The Netherlands. He is co-founder of KnowledgeWorks a software company that develops software to support learning and knowledge management and he facilitates a Dutch online workshop on the foundations of communities of practice in collaboration with Cpsquare.

Vic Lally is a Researcher, Educator and Consultant in collaborative e-learning in higher education and he is Director of Learning and Teaching for the Faculty of Social Sciences at the University of Sheffield (UK). He has directed many national and international research programmes in e-learning and collaboration, and produced over 60 publications in the field. Current projects include E-China with Huang Ronghuai of the School of Networked Education at Beijing Normal University, Theorising Learning with Maarten de Laat at Exeter University, and Creative Collaborations with Maarten de Laat and Maddy Sclater of Glasgow University.

Dr. Lasse Lipponen is a university Lecturer and works for the University of Helsinki at the Department of Applied Sciences of Education. His main research area is collaborative and technology-mediated practices of learning and working.

Professor. Robert-Jan Simons graduated in Psychology (educational and developmental) at the University of Amsterdam in 1973 and worked as a Researcher in the Universities of Nijmegen and Tilburg. His PhD on the role of concrete analogies in learning took place at the University of Tilburg (1981). From 1990 to 2001, Simons was Professor of Educational Psychology at the University of Nijmegen, where he directed the Research Institute for Pedagogy and Education. Since 2001, he has a chair at Utrecht University focusing on learning with ICT. He is Director of the Centre for ICT in education. His main research interests are on-the-job learning, constructivist learning theories and computer-supported collaborative learning.

\section{Introduction}

The aim of this paper is to study the nature of online learning within two Networked Learning Communities (NLCs). By Networked Learning (NL), we mean the use of internet-based information and communication technologies to promote collaborative and cooperative connections: between one learner and other learners; between learners and 
tutors; between a learning community and its learning resources, so that participants can extend and develop their understanding and capabilities in ways that are important to them, and over which they have significant control (Banks et al., 2003, p.1). The notion of learning in communities (Wenger, 1998) has changed the way we experience teaching and learning in NL. It is no longer seen as desirable that the teacher is in full control; learners are encouraged to actively take responsibility and start to coordinate and regulate their own (collaborative) learning (Anderson et al., 2001; Jones et al., 2000). Researchers in NL are pointing to a changing teacher-student relationship (McConnell, 1999; Rimmershaw, 1999; Vonderwell, 2003). The teacher is becoming a 'guide on the side', implying that students are being stimulated to take active control over their own and collaborative learning processes. This requires students to explicitly schedule their activities and assign roles within the group, instead of just focusing on course content (Strijbos et al., 2004) and there is a growing evidence for students participating in collaborative and community-based learning activities to learn and help each other with their project (Light et al., 2000; McAlpine et al., 2004; Schellens and Valcke, 2002; Veldhuis-Diermanse, 2002; Vonderwell, 2003). As such, members of a NLC may be seen as both learner and tutor (De Laat and Lally, 2003).

This article is part of a continuing study in NL where the focus is on developing an evidence base for learning and teaching processes in NLC as a way of informing both theory and praxis. This will enable us to increase our understanding of what is actually happening when participants are engaged in networked teaching and learning activities. In this article we present students' involvement with NL. Our previous paper (De Laat et al., 2005) is concerned with the teachers' experiences working with the same NLCs and presented some findings with respect to two different teaching styles employed by the teachers (Brian, an experienced teacher builds on previous experiences and knowledge of what can be expected, whereas Seline, who is a beginning teacher on the course struggles in the absence of such understandings). Teaching online requires different, and often new, skills for the teacher, as well as a different attitude towards teaching or being a teacher. This is partly due to the open learning environment and the use of constructivist and community-based learning principles in the design of many NL courses. This changes the role of students from passive to active learners. The main focus of this article is on the students' behaviour, in order to provide a more holistic and complementary analysis of these two NLCs. In particular, we are interested in understanding the teaching and learning activities employed by the participants in these NLCs, to understand the way roles, tasks and strategies emerge as the NL collaborators shape their collective endeavour through an online discussion.

Our research in NL is based on the idea that community-based learning principles provide an open learning environment where students can construct knowledge together. When learning collaboratively, students create the opportunity to share and discuss their experiences and knowledge in a way that may benefit both the individual as well as the community. Learning in communities is a process where both individual and collective learning goals and agendas are carefully and constantly being negotiated, around a topic or domain that is of interest to each participant. In this way NLCs enable the learners to develop a space for a shared activity in which their learning is situated. Here they connect ideas, share problems and insights in a constructive way, and connect with concepts with which they are already familiar, using new knowledge that is collaboratively constructed through their dialogues and social interactions online. This view of socio-culturally mediated, situated and constructive community-based 
learning is the main theoretical perspective that drives the design of the Master's in Networked Learning course at Sheffield University, offered since 1996. The theoretical underpinnings and their relationship to learning and teaching design are summarised as follows (EQUEL Position Paper, 2004):

- The problems and issues researched by the groups are defined by the groups themselves through processes of negotiation.

- The problems and issues have a personal and professional focus. They are important to the members of the group, arising from concerns and interests they may have about their professional practice.

- Problems require negotiation and communication to understand them. Because the issues researched are complex and ill-defined, the members of each group have to engage in considerable communication in order to understand them and in order to negotiate changes in their perception of the 'problem' and its resolution as their work progresses.

- Communication is both task-oriented and socially centred. The groups function as learning communities which have an interest in sharing, supporting and learning collaboratively in a social context, and which develop understanding of what it means to learn together in a networked environment.

- The groups are encouraged to view their research and learning as 'action research', and they are introduced to the concept of action research in an earlier e-seminar. This provides them with a model of how to work together, which helps guide them in their collaborations.

- $\quad$ They require a journey of learning. There are no specific pre-defined learning outcomes. Each group embarks on a learning journey that requires collaboration but which does not define in exact detail how they should work together or what the outcomes of their learning should be.

- They involve a high degree of reflexivity. Learning in these groups is highly experiential, and the groups are therefore encouraged to be reflective and to use this as a source of learning.

A means for achieving this is exposure to other participants' development within the learning community. Members participate in developing the learning community perspective, which is based on participants and teachers taking collective responsibility for the (re)design and evaluation of the programme (EQUEL Position Paper, 2004).

\section{Methods}

\subsection{Sample}

The Master's Programme in E-Learning is based upon the establishment of a 'research learning community' among the participants and the university teacher. Activities are undertaken around five 'workshops' over a two-year period. The programme is entirely online and hosted in the virtual learning environment WebCT. The students are mainly mid-career professionals, many of whom have post-graduate experience of higher education, are engaged with teaching responsibilities, and often charged with developing 
e-learning within their own organisation. The analysis is based upon collaborative project work conducted by two NLCs. NLC1 consists of seven students and one teacher. NLC2 consists of nine students plus one teacher. We divided the ten-week period into three sections: beginning, middle and end. This allowed us to take a timeline analysis approach. From each period we took a ten-day sample to form our data set. This resulted in a selection of 235 messages in NLC1 and 215 messages in NLC2.

\subsection{A multi-method approach}

In order to provide a more holistic and complimentary description of their participation in the NLCs, we developed a multi-method research approach. In research terms, much is still unclear about the effective forms of NL and there is a need for more empirical descriptive research to provide an evidence base for the paedagogical processes both teachers and students are engaged in. Hakkinen et al. (2003) suggested a multi-method approach that is process-oriented and takes into account different contextual aspects of NL. They argue that research is needed that captures the process and organisation of collaborative interaction and its contribution to learning:

\footnotetext{
"Methods should be developed not only for capturing processes and outcomes of learning, but also experienced effects and individual interpretations of participation in CSCL settings." (Hakkinen et al., 2003, p.402)
}

The aim of this kind of research is to provide a more complete picture of NL processes. We think it is important that this research is focused on the central processes of NL, that is: learning and teaching. We believe that these understandings will contribute to the development of better paedagogical frameworks and software that more effectively support learning and tutoring through paedagogical design. We have developed a multi-method research framework to study NL processes by making use of Social Network Analysis (SNA) to find out 'who is talking to whom', Content Analysis (CA) through coding teaching and learning activities as a way to find out "what they are talking about', and Context Analysis (CxA) focusing on the experiences of the participants to find out 'why they are talking as they do'.

Figure 1 Multi-method research framework for studying networked learning

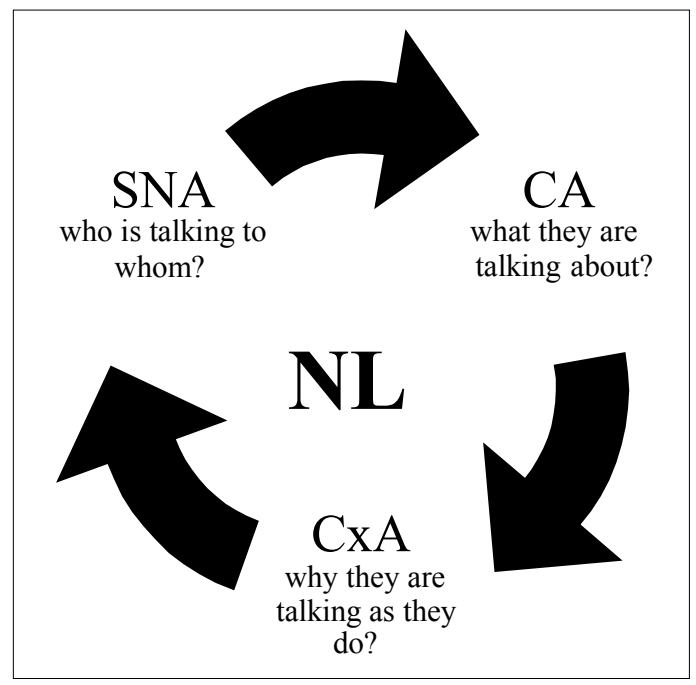


These three methods are used to triangulate and contextualise our findings and to stay close or connected to the first-hand experiences of the participants themselves (De Laat et al., 2005).

To find out who is talking to whom, we used SNA to study the way people participated and interacted with each other. Logged information from WebCT can be stored away in a case-by-case matrix (based on writing and responding activities) to analyse interaction patterns. We used UCINET (an SNA package) to make the visualisations of the relationships within the network. For this study we chose a sociogram representing the connections between the participants and the direction of incoming and outgoing messages (Wasserman and Faust, 1997).

The following step of our analysis was concerned with finding out what they are talking about. The central purpose of CA is to generalise and abstract the complexity of the original messages in order to look for evidence of learning and tutoring activities. In order to probe collaborative NL (learning and tutoring) we 'coded' the contributions using two coding schemas (De Laat and Lally, 2003).

The first coding schema, developed by Veldhuis-Diermanse (2002), was used to code units of meaning that were regarded as 'on the task', focusing on the learning processes used to carry out the task. This schema includes four main categories: cognitive activities used to process the learning content and to attain learning goals; metacognitive knowledge and metacognitive skills used to regulate the cognitive activities; affective activities, used to cope with feelings occurring during learning, and miscellaneous activities. We decided to exclude miscellaneous category in our analysis since we are interested in the evidence of learning activities. The second schema is used to code units of meaning that are 'around the task' where the focus is on tutoring (Anderson et al., 2001). This schema includes three main sub-categories: design and organisation, facilitation of discourse and direct instruction. Our intention here was to attempt to reveal the ways in which the participants were facilitating and regulating each other's learning, while undertaking the workshop project task. Codes were assigned to parts of messages based on semantic features such as ideas, argument chains, and topics of discussion (Chi, 1997). Capturing these activities using strict syntactic rules was not possible because of the elaborate nature of a discussion. We chose to use NVivo software to help us to partially automate this process: to highlight segments of the text with coding that we claim represents a particular learning or tutoring activity. In effect, these coded segments were our units of meaning. NVivo was also used to conduct searches of the coded data, in order to produce summary tables (see Tables, below). To determine our inter-coder reliability we firstly, for each coded message, checked to see if the codes assigned by the two coders referred to the same parts of the message (i.e., the same units of meaning). Secondly, we checked to see if the two coders had assigned the same codes to each unit. Based on a $10 \%$ sample of all the messages coded by the two researchers, a Cohen's Kappa of 0,86 was established.

The final step of this study aimed to highlight students' experiences as a way to find out why they are talking as they do. CXA can be done using several techniques, like interviews, Critical Event Recall (CER), Thinking Out Loud (TOL), course evaluation forms, student diaries, etc. Student self-assessment reports were used in this paper to collect information about the student experiences. These reports were organised around the following topics: product achievement, communication skill, social relationships and 
reflective skills. The students were instructed to reflect on their NLC experiences and to read through the messages to recall the entire event and to make references in their self-review to particular messages to substantiate the issues addressed in their reports.

\section{Results}

Starting with SNA analysis (see Figures 2 and 3), it is clear that participation over time is dynamically changing, and within both groups the participants are more interconnected in the middle phase than in the other two phases. In Group 1, the overall tendency is to act as a group; there are central and peripheral participants, but the interaction patterns are not centralised (a star shape) around a few 'dominant' participants. Also, different phases have different members operating in the centre of the groups' interaction. Brian, for instance, moves to the side after the beginning phase. Danton stays relatively central but moves to the side in the ending phase, whereas Anka (for instance) takes a central position. Mort, after being silent in the beginning, starts making modest connections with the group. Ryan, though rather active throughout, makes a strong appearance in the middle phase alongside Mary.

Figure 2 Interaction patterns of beginning, middle and end phase of Group 1
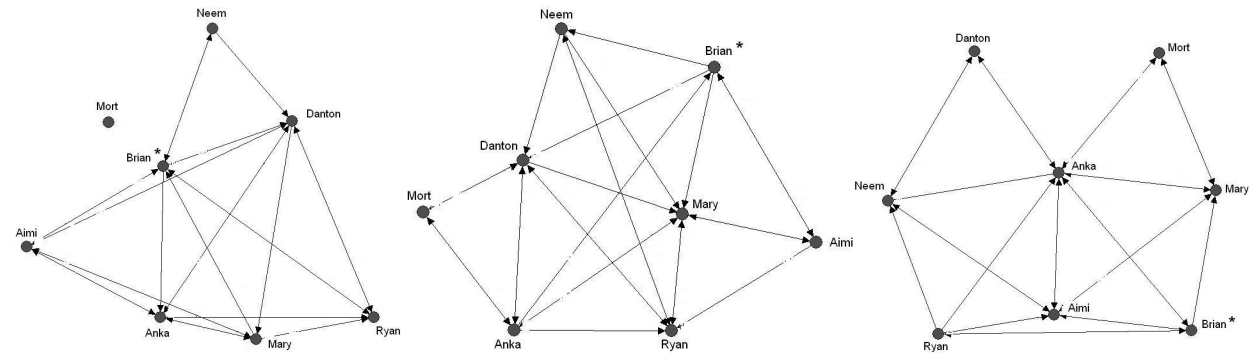

Note: $\quad$ Pseudonyms are used here and in the rest of this paper. An * symbol denotes the university-designated tutor in all figures and tables

Figure 3 Interaction patterns of beginning, middle and end phase of Group 2

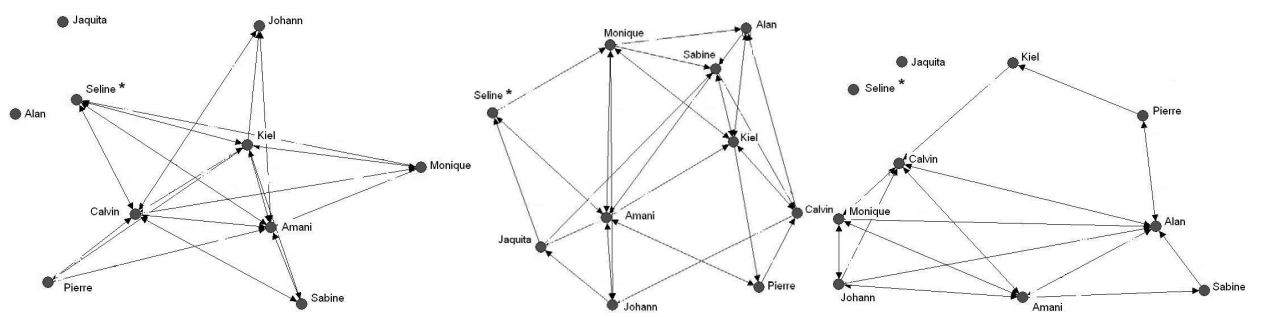

Group two shows a different dynamic. The interaction seems to change more drastically throughout the phases. In the beginning the interaction is rather centralised around three participants (Kiel, Calvin and Amani), where the middle phase is characterised by a more overall group structure. The ending phase seems to be organised around a few participants who are 'still' actively involved, and some participants (including the 
teacher, Seline) have not made a contribution at all (note that this data is only a sample of ten days in each phase). Amani keeps a central presence over the entire period, and so does Monique. Alan gets more involved as the project moves on, where Kiel steps relatively aside in the ending phase.

In Tables 1 to 6 , we present summary tables of the CA to identify learning and tutoring processes in Brian's group. One of the general outcomes of Group 1 is the strong increase of learning activities in the middle phase (while the tutoring activities stay relative stable), only to decrease in the ending phase. There is a strong increase of both cognitive and metacognitive units coded in the middle phase. Affective learning activities remain relatively stable throughout, indicating a continuing expression of group feelings about their learning processes. Among the tutoring activity, there is a strong tendency for group members to help each other, as well as to engage with the instructional design (though this decreases towards the end). Anka and Aimi contribute extensively for both learning and tutoring. Mary behaves similarly, but her engagement drops in the ending phase. Danton is more active as a learner (beginning and middle); Ryan and Mary develop a strong interest for the learning task in the middle, and Neem starts to get heavily engaged in both learning and teaching.

Table 1 Units of meaning coded for learning processes during the beginning phase of Group 1

\begin{tabular}{lccccccccc}
\hline \multirow{2}{*}{$\begin{array}{l}\text { Type of learning } \\
\text { process }\end{array}$} & \multicolumn{7}{c}{ Learning processes of individual community members } \\
\cline { 2 - 10 } & Brian* & Ryan & Mary & Danton & Anka & Aimi & Neem & Mort & Total \\
\hline Cognitive & 5 & 2 & 4 & 4 & 6 & 1 & 2 & 0 & 24 \\
Affective & 3 & 1 & 4 & 4 & 3 & 0 & 0 & 0 & 15 \\
Metacognitive & 1 & 0 & 4 & 2 & 3 & 2 & 1 & 0 & 13 \\
Total & 9 & 3 & 12 & 10 & 12 & 3 & 3 & 0 & 52 \\
\hline
\end{tabular}

In the beginning phase, it is evident that, except for Mort, all the participants are in some ways involved in learning activities, conceptualising the task ahead. Danton, Mary and Anka are the strongest contributors. One can say that all activities are equally spread over the participants. Among the members, there is a strong emphasis on making cognitive $(46 \%)$ statements to each other (debating ideas, using and linking new information). Of the coded units, $29 \%$ are affective, i.e., emotional responses to options of other students' task content, and $25 \%$ of the codes refer to metacognitive units. It is interesting to see that Brian, the teacher, is present with respect to the learning processes.

Table 2 Units of meaning coded for learning processes during the middle phase of Group 1

\begin{tabular}{lcrrrrrrrrr}
\hline \multirow{2}{*}{$\begin{array}{l}\text { Type of learning } \\
\text { process }\end{array}$} & \multicolumn{7}{c}{ Learning processes of individual community members } \\
\cline { 2 - 10 } & Brian* & Ryan & Mary & Danton & Anka & Aimi & Neem & Mort & Total \\
\hline Cognitive & 0 & 11 & 21 & 8 & 19 & 7 & 5 & 4 & 75 \\
Affective & 0 & 8 & 4 & 4 & 3 & 7 & 6 & 3 & 35 \\
Metacognitive & 0 & 16 & 10 & 1 & 4 & 5 & 15 & 1 & 52 \\
Total & 0 & 35 & 35 & 13 & 26 & 19 & 26 & 8 & 162 \\
\hline
\end{tabular}


In this phase, all the learning activities have increased for all the students of this group, though compared to the previous phase, the cognitive and metacognitive units have made a strong increase. At this point the participants are discussing and reflecting on their task. Mort has started to get involved while Brian stopped making contributions to the learning task of this group. With respect to cognitive contributions, both Mary and Anka increased, as well as Ryan to some extent. Affective units increased as well and were coded across the group. Ryan, Mary and Neem started to make metacognitive statements, reflecting on the content and keeping clarity in the discussion.

Table 3 Units of meaning coded for learning processes during the ending phase of Group 1

\begin{tabular}{lcccccccccc}
\hline \multirow{2}{*}{$\begin{array}{l}\text { Type of learning } \\
\text { process }\end{array}$} & \multicolumn{7}{c}{ Learning processes of individual community members } \\
\cline { 2 - 10 } & Brian* & Ryan & Mary & Danton & Anka & Aimi & Neem & Mort & Total \\
\hline Cognitive & 0 & 2 & 2 & 0 & 4 & 8 & 0 & 1 & 17 \\
Affective & 3 & 2 & 5 & 1 & 4 & 1 & 0 & 4 & 20 \\
Metacognitive & 0 & 0 & 2 & 0 & 3 & 2 & 0 & 0 & 7 \\
Total & 3 & 4 & 9 & 1 & 11 & 11 & 0 & 5 & 44 \\
\hline
\end{tabular}

In this phase, both the cognitive (39\%) and metacognitive (16\%) coded units have dropped considerably, while the affective learning processes increased (45\%), indicating that the learning task is coming to an end and the group is mainly commenting on the work they have done. It seems that during this phase mostly Anka, Aimi and Mary are engaged in learning activities, and also Brian has started to get involved in this again, making affective statements about the learning of the group.

Table 4 Units of meaning coded for tutoring processes in the beginning phase of Group 1

\begin{tabular}{lrrrrrrrrrr}
\hline \multirow{2}{*}{$\begin{array}{l}\text { Type of tutoring } \\
\text { process }\end{array}$} & \multicolumn{7}{c}{ Tutoring processes of individual community members } \\
\cline { 2 - 10 } & Brian* & Ryan & Mary & Danton & Anka & Aimi & Neem & Mort & Total \\
\hline Direct instruction & 7 & 0 & 2 & 0 & 5 & 5 & 0 & 0 & 19 \\
Facilitation & 11 & 11 & 11 & 5 & 15 & 8 & 3 & 0 & 64 \\
Instructional design & 9 & 8 & 12 & 1 & 15 & 8 & 1 & 0 & 54 \\
Total & 27 & 19 & 25 & 6 & 35 & 21 & 4 & 0 & 137 \\
\hline
\end{tabular}

With respect to tutoring activities in the beginning phase, again, Brian, Mary and Anka are the strongest contributors. Direct instruction $(14 \%)$ is taken up mostly by the teacher, though two students (Anka and Aimi) were involved in this as well. Also a few of the participants, again, Anka and Mary, were more involved with the instructional design (39\%) of the collaborative project. This might suggest that of the group, Anka and Mary were mostly concerned with organising the group's activity while almost all the participants were engaged in facilitative activities (47\%) towards each other. 
Table 5 Units of meaning coded for tutoring processes in the middle phase of Group 1

\begin{tabular}{lccccccccc}
\hline \multirow{2}{*}{$\begin{array}{l}\text { Type of tutoring } \\
\text { process }\end{array}$} & \multicolumn{7}{c}{ Tutoring processes of individual community members } \\
\cline { 2 - 10 } & Brian* $^{*}$ & Ryan & Mary & Danton & Anka & Aimi & Neem & Mort & Total \\
\hline Direct instruction & 6 & 0 & 1 & 0 & 1 & 0 & 2 & 0 & 10 \\
Facilitation & 9 & 15 & 16 & 4 & 11 & 5 & 12 & 4 & 76 \\
Instructional design & 3 & 11 & 8 & 2 & 4 & 11 & 13 & 4 & 56 \\
Total & 18 & 26 & 25 & 6 & 16 & 16 & 27 & 8 & 142 \\
\hline
\end{tabular}

Tutoring in this phase stays relatively unchanged (Direct instruction (7\%), Facilitation (53\%) and Instructional design (40\%) activities). Neem has started to take a strong tutoring interest (from 4 to 27) as well as Mort to some extent, while Anka was more focused on learning activities during this phase, similarly with Danton and Aimi.

Table 6 Units of meaning coded for tutoring processes in the ending phase of Group 1

\begin{tabular}{lccccccccc}
\hline \multirow{2}{*}{$\begin{array}{l}\text { Type of tutoring } \\
\text { process }\end{array}$} & \multicolumn{7}{c}{ Tutoring processes of individual community members } \\
\cline { 2 - 10 } & Brian* & Ryan & Mary & Danton & Anka & Aimi & Neem & Mort & Total \\
\hline Direct instruction & 1 & 0 & 0 & 0 & 1 & 1 & 2 & 0 & 5 \\
Facilitation & 8 & 7 & 5 & 3 & 17 & 21 & 2 & 5 & 68 \\
Instructional design & 2 & 2 & 4 & 0 & 4 & 5 & 1 & 0 & 18 \\
Total & 11 & 9 & 9 & 3 & 22 & 27 & 5 & 5 & 91 \\
\hline
\end{tabular}

During the last phase tutoring activities went down in general, and the contributions made within the group were less equally spread. Only Anka and Aimi were making a strong tutoring input, especially with respect to facilitation. Their involvement in both learning and tutoring is also supported by the SNA patterns in this phase, where they appear as central participants.

Tables 7 to 12 show the results of CA for learning and tutoring processes for Seline's group. In general we can see a similar pattern in this group, as both learning and tutoring contributions increase in the middle phase. There is a strong increase of both cognitive and metacognitive units coded in the middle phase. Affective learning activities remain relatively stable throughout. Among the tutoring activity, there is also a strong tendency to facilitate each other (with a high peak in the middle), as well as to engage with the instructional design, again with a peak in the middle phase. In contrast to the other group, the contributions made here seem to be less equally spread over the participants and participation changes considerably between the phases; the tables clearly show a low (or zero) contribution to the learning of the group by most of the participants (again at different stages) and a stronger involvement with tutoring in general. Overall, both Amani and Monique are strong contributors, both to learning and tutoring activities. Learning contributions in this group seemed to be mostly coming from Sabine, Calvin, Monique and Amani in the beginning; from Monique, Amani and Kiel in the middle, and from Calvin, Monique and Amani in the ending phase. With respect to tutoring, it seems that Sabine, Calvin, Monique and Amani take the lead in the beginning, especially Amani and Monique who take this forward in the middle, together with Sabine, Kiel and Jaquita. In the ending phase, most of the tutoring is undertaken by Amani, Monique, Calvin and Alan. 
In Table 7, we can see that $23(30 \%)$ units were coded for cognitive statements, and Sabine and Monique are mostly involved with this activity. Metacognitive processes are the largest category (31), representing $41 \%$ of all coded units. At this stage of the activity the group is still in the process of establishing relationships as a working group, and trying to understand and conceptualise the collaborative task it is about to undertake. Though SNA revealed that in this phase a few participants are central participants and there is not much communication between the participants as a whole.

Table 7 Units of meaning coded for learning processes during the beginning phase of Group 2

\begin{tabular}{lccccccccccc}
\hline \multirow{2}{*}{$\begin{array}{l}\text { Type of learning } \\
\text { process }\end{array}$} & \multicolumn{8}{c}{ Learning processes of individual community members } \\
\cline { 2 - 10 } & Seline* & Sabine & Calvin & Monique & Pierre & Amani & Johann & Kiel & Jaquita & Alan & Total \\
\hline Cognitive & 0 & 7 & 2 & 7 & 3 & 3 & 0 & 1 & 0 & 0 & 23 \\
Affective & 2 & 6 & 5 & 5 & 2 & 2 & 0 & 0 & 0 & 0 & 22 \\
Metacognitive & 0 & 6 & 10 & 1 & 3 & 9 & 0 & 2 & 0 & 0 & 31 \\
Total & 2 & 19 & 17 & 13 & 8 & 14 & 0 & 3 & 0 & 0 & 76 \\
\hline
\end{tabular}

Table 8 Units of meaning coded for learning processes during the middle phase of Group 2

\begin{tabular}{|c|c|c|c|c|c|c|c|c|c|c|c|}
\hline \multirow{2}{*}{$\begin{array}{l}\text { Type of learning } \\
\text { process }\end{array}$} & \multicolumn{11}{|c|}{ Learning processes of individual community members } \\
\hline & Seline* & Sabine & Calvin & Monique & Pierre & Amani & Johann & Kiel & Jaquita & Alan & Total \\
\hline Cognitive & 0 & 6 & 0 & 11 & 0 & 34 & 4 & 7 & 4 & 1 & 67 \\
\hline Affective & 0 & 0 & 1 & 2 & 0 & 12 & 2 & 0 & 4 & 0 & 21 \\
\hline Metacognitive & 0 & 0 & 0 & 19 & 0 & 27 & 0 & 5 & 1 & 0 & 52 \\
\hline Total & 0 & 6 & 1 & 32 & 0 & 73 & 6 & 12 & 9 & 1 & 140 \\
\hline
\end{tabular}

In the middle phase, Amani makes a very strong contribution to the learning of the group, which makes her stay at the centre of this group's interaction. Overall, the units coded during this phase were mainly contributed by Amani and Monique, suggesting they were more or less working together during this phase. Contributions of Calvin and Sabine decreased while Jaquita started to join (nine units were coded).

Table 9 Units of meaning coded for learning processes during the ending phase of Group 2

\begin{tabular}{|c|c|c|c|c|c|c|c|c|c|c|c|}
\hline \multirow{2}{*}{$\begin{array}{l}\text { Type of learning } \\
\text { process }\end{array}$} & \multicolumn{11}{|c|}{ Learning Processes of Individual Community Members } \\
\hline & Seline* & Sabine & Calvin & Monique & Pierre & Amani & Johann & Kiel & Jaquita & Alan & Total \\
\hline Cognitive & 0 & 0 & 6 & 2 & 0 & 12 & 3 & 0 & 0 & 2 & 25 \\
\hline Affective & 0 & 0 & 4 & 8 & 0 & 2 & 0 & 0 & 0 & 3 & 17 \\
\hline Metacognitive & 0 & 0 & 1 & 2 & 0 & 7 & 1 & 0 & 0 & 0 & 11 \\
\hline Total & 0 & 0 & 11 & 12 & 0 & 21 & 4 & 0 & 0 & 5 & 53 \\
\hline
\end{tabular}

Whereas in the other group we saw Brian reappearing in the discussion, no learning and tutoring units were coded for Seline. The group structure has changed again compared to the beginning and middle phase (see also Figure 3). For Sabine and Kiel (who made learning contributions in the previous phase) no units were coded, while the opposite 
behaviour can been seen for Calvin who reappeared (both cognitively and affectively), as well as Alan who started to make a strong appearance in this phase, whereas Jaquita seemed to have disengaged from the learning discourse again.

Table 10 Units of meaning coded for tutoring processes in the beginning phase of Group 2

\begin{tabular}{|c|c|c|c|c|c|c|c|c|c|c|c|}
\hline \multirow{2}{*}{$\begin{array}{l}\text { Type of tutoring } \\
\text { process }\end{array}$} & \multicolumn{11}{|c|}{ Tutoring processes of individual community members } \\
\hline & Seline* & Sabine & Calvin & Monique & Pierre & Amani & Johann & Kiel & Jaquita & Alan & Total \\
\hline Direct instruction & 7 & 0 & 1 & 0 & 0 & 3 & 0 & 0 & 0 & 0 & 11 \\
\hline Facilitation & 6 & 7 & 14 & 10 & 3 & 13 & 5 & 5 & 0 & 0 & 63 \\
\hline Instructional design & 3 & 5 & 10 & 4 & 1 & 17 & 0 & 4 & 0 & 0 & 44 \\
\hline Total & 16 & 12 & 25 & 14 & 4 & 33 & 5 & 9 & 0 & 0 & 118 \\
\hline
\end{tabular}

Tutoring processes, as indicated by coded units of meaning, are dominated by facilitation at this stage of the activity (see Table 2: 63 units (53\% of total)). Considerable group processing is also devoted to instructional design (44 units, 37\% of total) as members of the group help each other to be organised for the task ahead.

Table 11 Units of meaning coded for tutoring processes in the middle phase of Group 2

\begin{tabular}{|c|c|c|c|c|c|c|c|c|c|c|c|}
\hline \multirow{2}{*}{$\begin{array}{l}\text { Type of tutoring } \\
\text { process }\end{array}$} & \multicolumn{11}{|c|}{ Tutoring processes of individual community members } \\
\hline & Seline* & Sabine & Calvin & Monique & Pierre & Amani & Johann & Kiel & Jaquita & Alan & Total \\
\hline Direct instruction & 3 & 0 & 1 & 0 & 0 & 5 & 0 & 1 & 0 & 0 & 10 \\
\hline Facilitation & 1 & 8 & 2 & 33 & 4 & 60 & 5 & 11 & 6 & 1 & 131 \\
\hline Instructional design & 0 & 4 & 2 & 15 & 1 & 35 & 1 & 2 & 6 & 3 & 69 \\
\hline Total & 4 & 12 & 5 & 48 & 5 & 100 & 6 & 14 & 12 & 4 & 210 \\
\hline
\end{tabular}

The students for whom learning activities were coded (Sabine, Monique, Amani, Kiel and Jaquita), also contributed as tutors during this phase. Again facilitation (62\%) processes are dominating (again Amani makes a very strong contribution here) but there is also some activity on instructional design (33\%).

Table 12 Units of meaning coded for tutoring processes in the ending phase of Group 2

\begin{tabular}{|c|c|c|c|c|c|c|c|c|c|c|c|}
\hline \multirow{2}{*}{$\begin{array}{l}\text { Type of tutoring } \\
\text { process }\end{array}$} & \multicolumn{11}{|c|}{ Tutoring processes of individual community members } \\
\hline & Seline* & Sabine & Calvin & Monique & Pierre & Amani & Johann & Kiel & Jaquita & Alan & Total \\
\hline Direct instruction & 0 & 0 & 0 & 0 & 0 & 1 & 1 & 1 & 0 & 0 & 3 \\
\hline Facilitation & 0 & 3 & 7 & 13 & 3 & 12 & 8 & 2 & 0 & 8 & 56 \\
\hline Instructional design & 0 & 3 & 9 & 4 & 1 & 6 & 5 & 1 & 0 & 2 & 31 \\
\hline Total & 0 & 6 & 16 & 17 & 4 & 19 & 14 & 4 & 0 & 10 & 90 \\
\hline
\end{tabular}

Here, again, we see a similar shift in contributions, as described in the previous phase and the learning activities of this phase. Some active participants of the previous phase (Seline, Kiel and Jaquita) made way for others (Calvin and Alan). The main focus of the tutoring discourse was on facilitation $(62 \%)$ and instructional design (34\%). 
The overall patterns emerging from these summary tables indicate that Group 1 shows a relatively stable and continuous contribution pattern by their participants, whereas in Group 2 each, phase seems to have different participants, either moving away or back to the centre of the learning and tutoring discourse. The teacher in this group has been gradually fading out of the discourse. Two participants stayed central throughout the entire period (Monique and Amani), which might suggest that they were collaborating on the project together quite closely throughout.

Turning now to the analysis of self-assessment reports, the following section represents statements from the students about their experiences.

In Group 1, Brian (a more experienced teacher on this MEd) applied a 'proven to be successful' framework to teach this course, building in advanced organisers to support emergent community learning or to act as scaffolding, available for the students when needed (De Laat et al., 2005). The tutor in this group had more experience of NL, knowing when to intervene, and when to let the group support itself as it progressed with its task.

Aimi, who made considerable and consistent learning and tutoring contributions throughout, commented that when working on the product:

"Initially I found it difficult to find material but found websites posted by Ryan and Mary helpful.

Brian's comments were helpful and were important in helping me achieve my goals and allowed us to expand the project area."

Anka, who had a similar contributing style reported that:

"My participation during the project was persistent, corresponding to problems that could arise, constantly providing ideas and research results.

I participated in the exchange of information and asked for consensus from my partners, before making any conclusions, appreciating that the opinions and ideas of other persons, could have a valuable and positive influence on my thoughts."

Danton, who seemed to be more engaged with the learning rather than tutoring, commented:

"I think that I was a bit reactive rather than proactive in deciding what we were going to do. I didn't offer my own ideas for a project title or area within which we should work, but rather saw what others had suggested and voted for which one I thought would be most interesting to me.

I don't believe that I acted as a real team member. I did meet deadlines, but I feel that I would have been more able to build on comments and ideas from others had I been present more often during a crucial part of the project."

Ryan, who was mostly active in the middle phase, indicated that:

"I started a discussion thread with some ideas but realised that Neem had developed some ideas already and in more detail. We conversed regularly and commented on each other's initial work to help shape our contribution."

On the aspect of group communication and social relationships, Aimi reflected she tried to be supportive to the group:

"In order to ensure that everyone understood what we were doing, I tended to try and summarise where we were and who was doing what. 
At first in discussions about the product I made suggestions, but found that when there were no answers to my postings (even disagreements would have been nice), I became frustrated and tended to take more of a backseat in making major decisions. In retrospect, perhaps I should have communicated these feelings to the group."

Anka commented on the:

“...friendly and collaborative atmosphere created by all the members. I felt responsible for the progress and the wealth of the whole group. This kept me highly motivated."

At the same time, she found it more difficult to maintain relationships:

"This is an area that I consider myself to be weaker, as well as the area of being reflective. During the project I focused more on the aspects that had to do with the process of our work (like organizational issues, exchange of ideas, development of proposals)."

Danton, who is more used to working alone, commented:

"I was never at any point overtly encouraging, avoiding to extremely patronizing, aside from comments like 'I think that is a good idea', I praised no one.

I feel that I work better alone and that this has been made evident to the others."

Ryan stated:

"At times I was getting lost with conversations and whilst I think the learning set has developed social relationships over the last few months, it still seems to be on a 'work' level rather than on a 'social' level."

Reflecting on the overall experience, Aimi commented:

"I feel I have learned more about how I cope in situations where I feel I do not know people. For example instead of making a comment about how I felt I became quiet. This, I found, looking through a lot of the postings, was a common coping mechanism of mine - I tended to rant and rave offline (as it were). I have found this interesting as normally, I make my feelings known and always put my point of view across."

According to Anka:

"More effort on summarizing attitudes and behaviors, analysis of the group's behavior and expression of this analysis, could have made the whole collaborative procedure more qualitative and the group's cooperation more effective.

At the same time, I observed my reactions and I found out that sometimes I acted with stress and panic, while some other times, I focused too much in the process and tended to neglect the feelings and the problems of my partners. Somehow, looking at the list of my messages, I found out that I hesitated very much to express such reflective thoughts in the discussion threads."

Danton, reflected:

“...that feelings of guilt for not being around throughout the project could be alleviated by better time management. I have learned that it is extremely important to stay in touch with others to fully benefit from (and, obviously, contribute to) the learning process." 
In the second group, the beginning teacher (Seline) felt overwhelmed by the experience and wondered about her role, and whether she had the skills to teach online. Amani, who was a strong contributor (learning and tutoring) throughout commented that:

"At the start, Seline gave reassurance of her confidence in our ability, and offered direction. The group worked extremely effectively at the start, skills were coming to the fore, and my enthusiasm and a degree of awesome fear got me moving."

Monique was concerned that finding a way to collaborate was a real objective of participation:

"I created a schematic of roles/tasks/due dates to activate the members to volunteer and dialogue. With everyone's efforts, most especially the clarifications provided by Calvin, Amani, and Kiel in the area of setting up the organization of our work, we refined this to firm up an excellent framework."

Alan, whose contribution intensified as the project developed, reflected that his:

"...achievement was the design and building of the website. It was the area I was most comfortable in tackling and felt that I could build the trust lost by doing a good job."

Sabine, who became less engaged during the course, mentioned:

"I participated in the group discussion and I co-wrote the staff role section of the assignment after reading the suggestions put forward by both Pierre and Seline.

I did regret that I suggested a website because I learnt how hard it is to design a site and failed to anticipate a limited contribution because of a change in home circumstances."

Amani commented on communication and social relationships. She saw herself as a group supporter (which is supported by the relatively high tutoring codes):

"One difficulty related in understanding Jaquita's initial approach to analysing task design. This was the nearest we came to a misunderstanding, and sorting this out required a mediator, a role which I seem to have assumed."

Monique's communication style was positive:

"Helping them [the group] cope with their own tensions. Alan was responsive in saying I helped brighten his day in one thread. I even composed a song for our set to help diffuse what I thought were tensions among the members!'

Alan commented that:

"This project, more than the previous meet and greet activities, made us work together and develop our online personalities. Through the project, I felt responsible to the group and wanted to make that effort. I felt that good relationships were made with several group members and a 'bonding' process started to develop. One can sense the real desire to do the best for each other."

According to Sabine:

"It hasn't been difficult to cultivate a friendly atmosphere in this group and this has been a very encouraging factor in my study. Though I often found the group's collective indecision and eagerness to discuss minutiae in order to defer a decision very frustrating (similar to Alan). This led to a longing to have some action and an irritation with the progress the group was making. 
I have had to be much more tolerant than I would normally be and have tried to inject some humour into postings which were written when feeling irritated to take the edge off how I was feeling."

When asked to reflect on the overall experience, Amani found that:

"Roles chosen [by participants] reflected skills possessed. Kiel, Sabine provided web frameworks which enabled identity of content with format. Calvin, Monique and myself each and variously offered up systems for planning and organisation; Sabine, Jacquita and Monique incisive thinking; Alan, web skills. Johann, along with Calvin and myself helped put it all together."

Though she also found that she would:

"Need to stand back more and allow the process of group thinking to take its course. I wonder what happens if people do not involve themselves and where the project goes, but maybe I need to have more trust in others."

Monique reflects that she tended:

“...to observe others' actions as well as my own, especially in the socio-emotional arena.

It is after going through the project that I realized how deliberate one must be in forming a learning community in the VLE. However, it becomes fulfilling when you see others trying to make the relationship work in spite of technological challenges."

Alan found:

“...the ending phase immensely rewarding. I feel it was the first real exercise that made me want to engage with the degree and the learning set as a whole [see Table 9 and 12]. I am starting to feel more positive towards the whole thing after wondering initially whether it was really what I wanted."

Sabine, felt many times:

"that I have been standing still, only to discover a few days later that I have indeed 'learnt' something, but that learning has not been immediately apparent."

\section{Conclusion and implications for NLC}

In this article, we have presented and analysed the learning and tutoring experiences of students from two NLCs working on the same course and the same workshop. Despite there being a great difference in the way the teachers were participating in these groups, there are no major differences found in the overall learning dynamics of the students in the two groups. Both groups follow a similar pattern, where most of the activities (both learning and tutoring contributions) are found in the middle phase of the project. In both groups there are a lot of cognitive, metacognitive and facilitative contributions emphasising the social nature of the learning, and providing further evidence that participants are trying to be responsive and supportive to each other as a continual process of learning and group regulation (Light et al., 2000; McAlpine et al., 2004; Vonderwell, 2003). It seems that these activities are frequently occurring throughout the entire project, yet at different phases we see varying engagement. Groups tend to develop 
their own way of working together and create a rhythm that suits the circumstances (Wenger et al., 2002). Knowledge of participants' activities as well as their engagement, in combination with their needs and desires will help teachers (or moderators of web-based communities) to develop models and design for NL that provide the right kind of support when needed, adapted to the particular phase they are in. This way, NL environments enable the learners to develop an open learning space for shared activity in which their learning is situated, where they connect ideas, share problems and insights in a constructive way with concepts they are already familiar with, and with new knowledge that is collaboratively constructed through their dialogues and social interactions online.

The course we have studied is designed to hand over many responsibilities to the community (EQUEL Position Paper, 2004), both in relation to the learning tasks as well as coordinating and regulating tasks. The relative absence of the beginning teacher, and her insecurity, did not emerge in the students' experiences as a central constraint upon their work. At the same time, and this emphasises the importance of a multi-method approach, participation patterns (based on SNA) between the two groups seemed rather different, Group 1 acted more as a stable group throughout, where as in Group 2, participation differed from phase to phase and the involvement with especially the learning task was not equally spread amongst the participants. The second group (based on CxA) worked out an explicit framework of roles and responsibilities to support their way of working together. This suggests that this group was dealing a lot with procedural issues while learning as a group. These findings imply that when developing models to support teaching and learning in NLCs, these dynamics should be taken into consideration. These are interesting emerging findings and further research is needed to study this potential relationship between teaching styles and group regulation by the students.

The self-assessment reports in combination with the other data inform us that NLCs are aware of creating this open learning space together and that it works because of having a shared activity that is clearly being negotiated. Students are self-regulative and aware of taking on roles and discuss them amongst the group to make their collaborative learning successful. Teachers do need to provide support - process and content, but they can also hand over more trust to the groups instead of 'worrying' if things are okay. Staying tuned in and connected with the group's process and work seems an important factor. It is important for both teachers and learners to develop insight about their learning and tutoring processes as well as their experiences. It is just not just enough to know what they are talking about. These findings indicate, we feel, the need for applying a multi-method approach to contextualise and relate the findings as a way to develop a context of understanding the complexity of NL. Researchers and NLCs should be provided (and should be able to create) feedback using SNA, CA and CxA repeatedly during their activity as a way to reflect more strategically on their performance and make decisions on how to move forward.

Early research in NL was mostly focused on the overall processes or outcomes of participant or teacher behaviour, using coding schemes (Gunawardena et al., 1997; Henri, 1992), questionnaires or student feedback (McAteer et al., 1997). More recently, a need for a mixed-method approach has been articulated - sometimes with a preference for a combination of quantitative and qualitative approaches (Hakkinen et al., 2003; Hammond and Wiriyapinit, 2004; Strijbos, 2004). However, one aspect that has been largely ignored in NL research is the dimension of time. By focusing on the overall experience or processes of learning and teaching, we are in danger of losing the development of this 
NL experience or how these learning and teaching processes evolve over time out of sight. Conducting time-line analysis in this case study by describing the beginning, middle and ending phase of NL activities is a way to address this. This research shows that:

- When describing processes, it is important to take into account that these processes are not static throughout time but have different dynamics at various stages of the collaborative work. More detailed knowledge of this process helps researchers and teachers (or moderators) develop more refined models for the support of NL.

- A multi-method approach is not only a way of taking multiple perspectives but also a way of contextualising and building up an understanding of the activities that participants are engaged in, by using the outcomes of one method to further understand the results of the next method. This way, a more complete understanding of the NL activities can be developed.

\section{References}

Anderson, T., Rourke, L., Garrison, D.R. and Archer, W. (2001) 'Assessing teaching presence in a computer conference context', Journal of Asynchronous Learning Networks, Vol. 5, No. 2, pp.1-17.

Banks, S., Goodyear, P., Hodgson, V. and McConnell, D. (2003) 'Introduction to the special issue on advances in research on networked learning', Instructional Science, Vol. 31, Nos. 1-2, pp.1-6.

Chi, M.T.H. (1997) 'Quantifying qualitative analyses of verbal data: a practical guide', Journal of the Life Sciences, Vol. 6, pp.271-313.

De Laat, M.F. and Lally, V. (2003) 'Complexity, theory and praxis: researching collaborative learning and tutoring processes in a networked learning community', Instructional Science, Vol. 31, Nos. 1-2, pp.7-39.

De Laat, M.F., Lally, V., Lipponen, L. and Simons, P.R.J. (2005) 'Teaching and learning in networked learning communities: a multi-method approach to analysing teachers' experiences with learning online', Manuscript Submitted for Publication.

EQUEL Position Paper (2004) Special Interest Group 3. E-learning Communities and Collaborative Learning, Coordinated by University of Sheffield, UK in Association with Aalborg University, DK, EU Commission E-learning Initiative.

Gunawardena, C.N., Lowe, C.A. and Anderson, T. (1997) 'Analysis of global online debate and the development of an interaction analysis model for examining social construction of knowledge in computer conferencing', Journal of Educational Computing Research, Vol. 17, No. 4, pp.397-431.

Hakkinen, P., Jarvela, S. and Makitalo, K. (2003) 'Sharing perspectives in virtual interaction: review of methods of analysis', in B. Wason, S. Ludvigson and U. Hoppe (Eds.) Designing for Change in Networked Learning. Proceedings of the International Conference on Computer Support for Collaborative Learning, Dordrecht: Kluwer, pp.395-404.

Hammond, M. and Wiriyapinit, M. (2004) 'Carrying out research into learning through online discussion: opportunities and difficulties', in S. Banks, P. Goodyear, C. Jones, V. Lally, D. McConnel and C. Steeples (Eds.) Proceedings of the Fourth International Conference on Networked Learning, Lancaster: Lancaster University, pp.456-462.

Henri, F. (1992) 'Computer conferencing and content analysis', in A.R. Kaye (Ed.) Collaborative Learning Through Computer Conferencing, London: Springer-Verlag. 
Jones, C., Asensio, M. and Goodyear, P. (2000) 'Networked learning in higher education: practitioners' perspectives', Association for Learning Technology Journal, Vol. 8, No. 2, pp.18-28.

Light, V., Nesbitt, E., Light, P. and Burns, J.R. (2000) “"Let's you and me have a little discussion”: computer mediated communication in support of campus-based university courses', Studies in Higher Education, Vol. 25, No. 1, pp.85-96.

McAlpine, I., Koppi, T., McLean, J. and Pearson, E. (2004) 'Course developers as students: a designers perspective of the experience of online learning', ALT-J, Research in Learning Technology, Vol. 12, No. 2, pp.147-162.

McAteer, E., Tolmie, A., Duffy, C. and Corbett, J. (1997) 'Computer-mediated communication as a learning resource', Journal of Computer Assisted Learning, Vol. 13, No. 4, pp.219-227.

McConnell, D. (1999) 'Examining a collaborative assessment process in networked lifelong learning', Journal of Computer Assisted Learning, Vol. 15, No. 3, pp.232-243.

Rimmershaw, R. (1999) 'Using conferencing to support a culture of collaborative study', Journal of Computer Assisted Learning, Vol. 15, No. 3, pp.189-200.

Schellens, T. And Valcke, M. (2002) 'Asynchrone discussiegroepen: een onderzoek naar de invloed op cognitieve kennisverwerking’, Pedagogische Studien, No. 79, pp.451-468.

Strijbos, J. (2004) 'The effect of roles on computer-supported collaborative learning', PhD Dissertation, Open Universiteit Nederland, Heerlen.

Strijbos, J.W., Martens, R.L., Jochems, W.M.G. and Broers, N.J. (2004) 'The effect of functional roles on group efficiency: using multilevel modeling and content analysis to investigate computer-supported collaboration in small groups', Small Group Research, Vol. 35, No. 2, pp.195-229.

Veldhuis-Diermanse, A.E. (2002) Csclearning? Participation, Learning Activities and Knowledge Construction in Computer-Supported Collaborative Learning in Higher Education, Wageningen: Grafisch Service Centrum Van Gils.

Vonderwell, S. (2003) 'An examination of asynchronous communication experiences and perspectives of students in an online course: a case study, Internet and Higher Education, Vol. 6, No. 1, pp.77-90.

Wasserman, S. and Faust, K. (1997) Social Network Analysis: Methods and Applications, Cambridge: Cambridge University Press.

Wenger, E. (1998) Communities of Practice: Learning, Meaning and Identity, Cambridge: University Press.

Wenger, E., McDermott, R. and Snyder, W. (2002) Cultivating Communities of Practice, Boston: Harvard Business School Press. 